\title{
Effect of Mechanical Vibration with Different Frequencies on Pore Structure and Fractal Characteristics in Lean Coal
}

\author{
Maoliang Shen $\mathbb{D}^{1},{ }^{1}$ Xuexi Chen $\mathbb{D}^{2},{ }^{2}$ and Yong Xu $\mathbb{D}^{3}$ \\ ${ }^{1}$ School of Safety Science and Engineering, Anhui University of Science and Technology, Huainan 232001, China \\ ${ }^{2}$ School of Safety Supervision, North China Institute of Science and Technology, Beijing 101601, China \\ ${ }^{3}$ School of Emergency Management and Safety Engineering, China University of Mining and Technology (Beijing), \\ Beijing 100083, China \\ Correspondence should be addressed to Xuexi Chen; learnchen1210@163.com
}

Received 18 February 2021; Accepted 3 September 2021; Published 22 September 2021

Academic Editor: Mickaël Lallart

Copyright (c) 2021 Maoliang Shen et al. This is an open access article distributed under the Creative Commons Attribution License, which permits unrestricted use, distribution, and reproduction in any medium, provided the original work is properly cited.

\begin{abstract}
The mechanical vibrations caused by underground operations can easily lead to coal and gas outbursts in coal mines. Using the MVGAD-I experimental platform that we designed, the raw coal $(0 \mathrm{~Hz})$ was treated with vibration frequencies of $25,50,75$, and $100 \mathrm{~Hz}$, and the coal samples with different frequency vibrations were obtained. The total pore volume (TPV), specific surface area (SSA), pore size distribution, and the pore fractal dimension (PFD) of five coal samples were analyzed by mercury intrusion porosimetry and low-pressure nitrogen adsorption data. We found that the TPV, SSA, and PFD of the coal samples fluctuate with the increase of vibration frequency. The changes of the TPV and SSA of coal samples treated with 25 and $75 \mathrm{~Hz}$ vibrations were significantly greater than those subjected to vibrations of 50 and $100 \mathrm{~Hz}$. Compared with the raw coal $(0 \mathrm{~Hz})$, the TPV and SSA of macropores, mesopores, and micropores increased the most in $75 \mathrm{~Hz}$ vibration coal sample. Therefore, the $75 \mathrm{~Hz}$ vibration excitation can improve the permeability of a body of coal mass and is conducive to the diffusion and seepage of coalbed methane and its production.. The influence of $25 \mathrm{~Hz}$ vibration on the TPV and SSA of macropores and mesopores is not obvious, but the TPV and SSA of minipores and micropores decrease significantly, which is not conducive to gas diffusion and adsorption. In addition, 25 and $75 \mathrm{~Hz}$ vibrations obviously damaged the fractal characteristics of both mesopores and micropores, resulting in the change of gas adsorption and diffusion ability. The rational use of a $75 \mathrm{~Hz}$ vibration is beneficial to both the production of gas and the prevention of outbursts, while a $25 \mathrm{~Hz}$ vibration should be avoided. The results are expected to reveal the microscopic mechanism of a vibration-induced outburst and provide theoretical guidance for employing the appropriate frequency of vibration to improve the rate of gas drainage and reduce the risk of outbursts.
\end{abstract}

\section{Introduction}

Coal and gas outbursts are one of the major disasters that threaten the safety of coal mine production [1-3]. Among recorded outburst accidents, the vast majority were induced by "small disturbances" that, in turn, were produced by blasting in mines and tunnels and drilling [4-9]. These "small disturbances" often provide energy for gas desorption, the crushing of coal, and the ejection of gas-solid mixtures in the form of vibrating at different frequencies (VDF) [10]. As a complex porous medium, coal has a dual-porosity system, which affects the adsorption and diffusion of gas in coal and the mechanical properties of coal [11-14]. Often, coal and gas outbursts occur in areas that have been disturbed by tectonism, and the coal bodies in those areas are then characterized as crumpled and cracked [15]. The vibration caused by a "small disturbance" may lead to a change in the pore structure of the coal, which has an important influence on its permeability, coal strength, elastic modulus, gas adsorption, and diffusion [16-20]. Therefore, it is of great significance to study how vibration affects the evolution of pores and fissures in the coal to reveal the microscopic mechanism of "small disturbances" that affect the instability of coal rock and the gas adsorption and diffusion characteristics of the coal seam. 
At present, some scholars have carried out research on the effect of vibration caused by "small disturbance" on the storage and transport of gas in coal and the permeability and mechanical properties of coal. Li et al. [5] concluded that vibration can reduce the coal's capacity to absorb gas but did not consider the differences caused by the vibration frequency in their research. Furthermore, some scholars take the vibration frequency as an important parameter by which to carry out adsorption and desorption experiments of gas in coal. Li et al. [7, 21, 22] concluded that a low-frequency mechanical vibration of $0 \sim 30 \mathrm{~Hz}$ is not conducive to the adsorption and desorption of gas in coal and will reduce the permeability of the coal and hinder the gas diffusion and seepage. In other words, the higher the frequency, the greater the likelihood that it will cause a local outburst. In contrast, Chen et al. [23] concluded that the shear force and thermal effect of a $30-100 \mathrm{~Hz}$ mechanical vibration on gas molecules can promote gas desorption and diffusion. While affecting the adsorption and desorption capacity of coal to gas, the stress wave generated by the vibration can also accelerate the development of internal cracks in the coal and rock mass, resulting in increased permeability of the coal rock [24-26], and the permeability increases exponentially with the increase of frequency [27]. In addition, from the perspective of fracture mechanics, $\mathrm{Li}$ et al. [5] asserted that vibrations will expand the cracks in the coal body and form a large-area network of fractures, which will reduce the strength of the body of coal which, in turn, would then be more prone to instability, thus increasing the risk of an outburst. At the same time, Ren and Pan et al. [28-30] also found that when the initial stress level reaches a certain critical state, a vibration has an obvious effect of cracking the body of coal, and the compressive strength and elastic modulus of the body of coal decrease significantly. Moreover, Li and Sun et al. [31, 32] believed that the closer the forced vibration frequency of coal and rock is to the natural vibration frequency, the more likely the coal and rock mass will be damaged and, thus, becoming unstable. There were a few studies on the evolution of the size of the pores in coal- ranging from micro- to nanoscale pores-caused by vibration. However, the nan and microscale pores and fissures are also directly related to the gas desorption and diffusion in the coal and the mechanical properties of coal $[16,33,34]$. Therefore, it is necessary to characterize the process of porefracture evolution in coal with VDF quantitatively in the range from micro- to nanopore sizes.

To date, the methods of qualitative and quantitative characterization of the pore structure of coal include mercury intrusion porosimetry (MIP), low-pressure nitrogen adsorption (LPNA), scanning electron microscopy (SEM), nuclear magnetic resonance (NMR), and small-angle X-ray scattering [35-39]. Researchers generally use a combination of the characterization methods of the MIP and LPNA tests to analyze the characteristics of micro- and nanoscale pores and fractures [14, 37, 40-42] and then analyze the influence of different pore-fracture characteristics on the adsorption, desorption, and diffusion of gas in coal $[43,44]$.

Fractal geometry is a powerful tool for quantitatively characterizing the morphology of pores and fractures in coal samples [20, 42, 45]. The fractal characteristics of coal are also one of the important factors affecting the adsorption, desorption, and diffusion of gas in the coal matrix $[13,37,46]$. The influence of vibration on the pore-fracture structure of a coal sample will inevitably lead to a change in the surface morphology characteristics of the pore-fractures $[38,47]$. However, a few studies use fractal geometry to quantitatively characterize the complexity of the porefracture surface morphology of coal samples under VDF.

Based on the shortcomings of the existing research, we selected tectonic coal from an outburst risk coal seam as the research object and used the methods of MIP and LPNA to quantitatively characterize the total pore volume (TPV), specific surface area (SSA), and pore size distribution (PSD) of coal samples under VDF. Based on the Menger and Frenkel-Halsey-Hill (FHH) models, the fractal dimensions of pores with different pore sizes under VDF were obtained by calculating MIP and LPNA data. And, in order to reveal the mechanism of vibration affecting gas permeability and diffusion in coal, this research deeply explores the evolutionary characteristics of pore structure in coal samples caused by vibrations which were caused by "small disturbances." This plays an important role in deeply understanding the mechanism of gas storage and transportation in coal and the mechanical change of coal under the influence of vibration and provides theoretical guidance for implementing engineering measures with different vibration frequencies to reduce coal and gas outburst accidents.

\section{Materials and Methods}

The MVGAD-I experimental device was designed to prepare coal samples with VDF. The pore and fracture distribution characteristics of the coal samples were quantitatively characterized by high-pressure mercury injection and lowtemperature liquid nitrogen adsorption. The pore fractal dimension of the coal samples was calculated by fractal theory combined with MIP and LPNA data. The flowchart of this study is shown in Figure 1.

2.1. Description of Coal Samples. The coal samples used in the experiment were collected at 15021 working face of Wangxingzhuang coal mine in Henan Province. The coal sample belongs to lean coal with the characteristics of being soft and broken. According to the standard GB/ T23561.1 2009 [48, 49], fresh coal samples were taken from the working face; transported to the laboratory; screened out, $0.25 \sim 0.5 \mathrm{~mm}$ coal samples; dried in a vacuum at $45^{\circ} \mathrm{C}$ for $8 \mathrm{~h}$; and prepared, $1500 \mathrm{~g}$ experimental samples. After the preparation of the coal samples, vibration experiments at different frequencies were carried out. Then, the coal sample was divided into five parts, each $200 \mathrm{~g}$; the remaining coal sample was reserved; and all coal samples were sealed.

2.2. Equipment. An MVGAD-I experimental device, which can carry out gas adsorption and desorption experiments under different vibration conditions (frequency and amplitude), was designed independently in the laboratory. The 


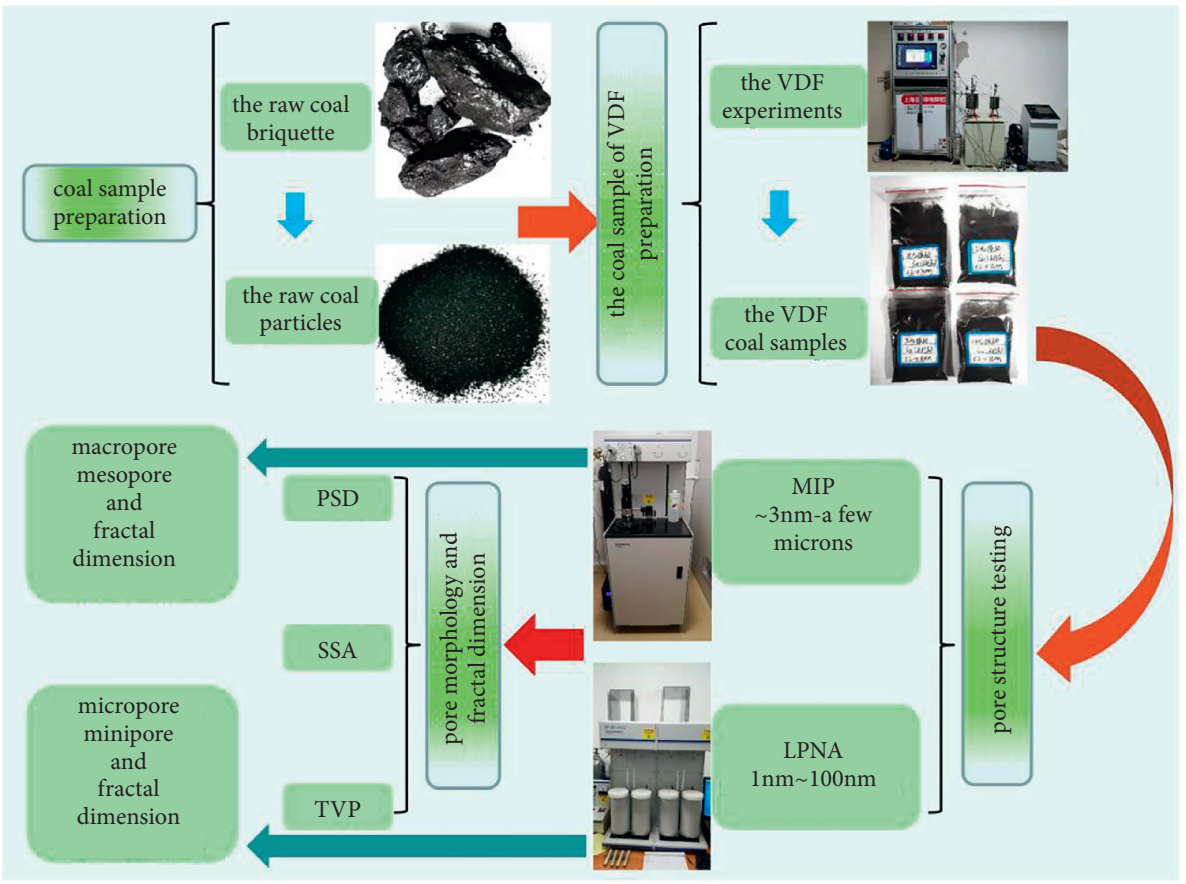

FIGURE 1: Experimental scheme to study the spatial characteristics and surface morphology of pores and fissures under VDF failure.

platform was composed of the gas supply subsystem, the vacuum degassing subsystem, the isothermal adsorptiondesorption subsystem, the mechanical vibration generation subsystem, and the data acquisition subsystem. The schematic diagram is shown in Figure 2.

The device can not only apply vibration excitation to a coal sample but also carry out gas adsorption and desorption experiments of coal samples at a constant temperature under vibration conditions. It has the following characteristics: (1) the vibration condition is adjustable. The device adopts an HX/ZD-TF electromagnetic vibration table, with an adjustable vibration frequency $(0 \sim 600 \mathrm{~Hz})$ and amplitude (0 5 mm). (2) Data automatic measurement and acquisition: the device can measure in real-time and collect the temperature (accuracy less than 0.5\%) and pressure (accuracy less than $0.5 \%$ ) and gas flow and velocity (accuracy less than 0.5\%). (3) The temperature is controllable. Temperature control $\left(10 \sim 75^{\circ} \mathrm{C}\right)$ at a constant temperature is realized by using an automatic heating belt and insulation layer.

\subsection{Vibration Excitation Experiments of Coal Sample. In the} coal mine site, the vibration frequency range caused by "small disturbances," such as blasting, drilling, coal cutting by shearer, and tunnelling, is $5 \sim 100 \mathrm{~Hz}[6,50,51]$. To characterize the influence of VDF on TPV, SSA, and PSD of the coal samples, mechanical vibrations with the frequencies of $0,25,50,75$, and $100 \mathrm{~Hz}$ were selected for the coal sample vibration experiment.

Before the experiment, the vibration frequency $(0 \sim 100 \mathrm{~Hz})$ and amplitude $(1 \mathrm{~mm})$ were set by the control panel, and the power was turned off after the parameters had been set. Then, we put the coal sample with the mass of $100 \mathrm{~g}$ after vacuum drying into the coal sample tank, turned on the power supply to carry out the vibration with different frequencies test of the coal samples, and set the vibration time to $20 \mathrm{~min}$. Finally, after vibrating under different frequencies, the coal samples were poured out of the coal sample tank and put into a sealed bag for sealed preservation, to conduct the pore and fissure characterization experiment.

2.4. MIP. According to ISO 15901 1:2005 (PSD and porosity of sturdy materials by mercury porosimeter and method adsorption, Part 1: mercury porosimeter) [48, 49], the MicroAutoPore IV 9500 mercury intrusion instrument (test aperture range $d>3 \mathrm{~nm}$, mercury injection pressure $0.1 \sim 413.05 \mathrm{MPa}$ ) was used to carry out the MIP test on the coal samples with frequencies of $0 \mathrm{~Hz}\left(\mathrm{~S}_{0}\right), 25 \mathrm{~Hz}\left(\mathrm{~S}_{25}\right), 50 \mathrm{~Hz}$ $\left(\mathrm{S}_{50}\right), 75 \mathrm{~Hz}\left(\mathrm{~S}_{75}\right)$, and $100 \mathrm{~Hz}\left(\mathrm{~S}_{100}\right)$, respectively, to obtain TPV, SSA, and PSD data on the pore-fissures.

The fractal dimension $D_{1}$ of pores in coal is calculated by formula (1) based on mercury injection data and using the Menger model and thermodynamic method [20, 37, 47]:

$$
\ln \frac{\mathrm{d} V_{p}}{\mathrm{~d} P} \alpha\left(D_{1}-4\right) \ln P,
$$

where $V_{p}$ represents the cumulative injection volume at a given pressure $\mathrm{P}, \mathrm{mL} / \mathrm{g}$; $\mathrm{P}$ represents the absolute injection pressure, $\mathrm{MPa}$; and $D_{1}$ represents the fractal dimension of the pores.

2.5. LPNA. According to the standard IOS15901 3: 2007 (PSD and porosity of solid materials by mercury adsorption and gas adsorption, Part 3: analysis of micropores by gas 


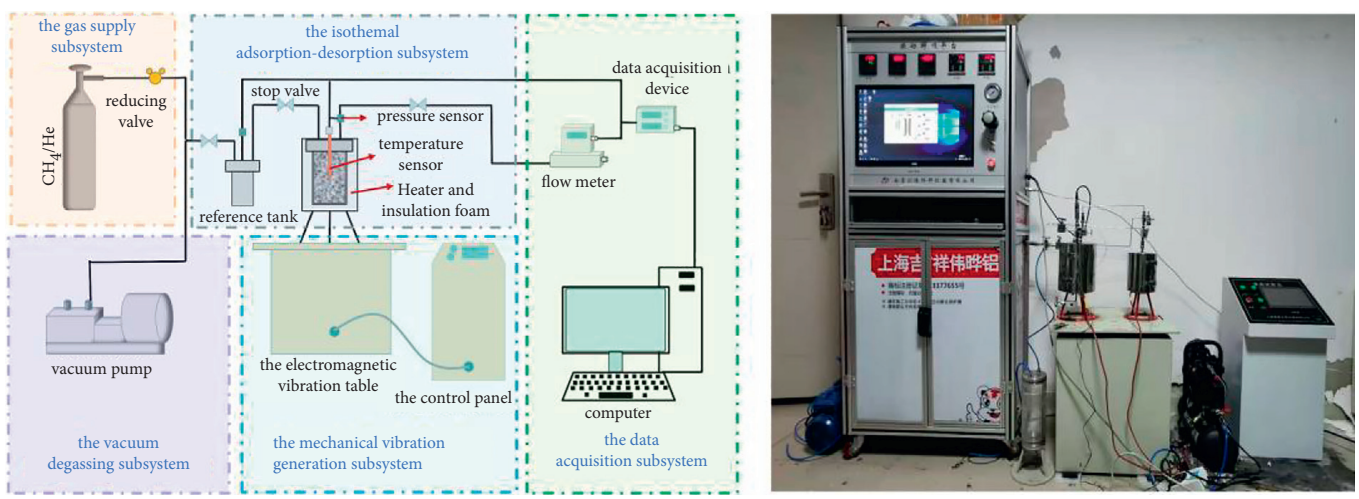

Figure 2: Schematic diagram of MVGAD-I experimental device.

adsorption [15, 49], the MicroActive software for the ASAP 2460 instrument was used to confirm the pore structure characteristics of the VDF coal samples at a temperature of $77 \mathrm{~K}$ and a relative pressure $\left(P / P^{0}\right)$ of $0.01 \sim 0.99$. The aperture test range of the instrument was $1.3 \sim 300 \mathrm{~nm}$. The density functional theory (DFT) was applied to quantify the adsorption-desorption isotherms, in which the TPV, SSA, and PSD of minipores and micropores were analyzed.

At present, the FHH fractal model is widely applied to calculate the adsorption data of LPNA and obtain the pore fractal dimension $[20,37,42]$ :

$$
\ln V=C+A\left[\ln \left(\ln \frac{P^{0}}{P}\right)\right]
$$

where $P$ represents the equilibrium pressure, $\mathrm{MPa} ; P_{0}$ represents the saturation pressure of methane gases, $\mathrm{MPa}$; $V$ represents the volume of adsorbed gases at the equilibrium pressure $p, \mathrm{~cm}^{3} / g ; C$ represents a constant; $A$ represents the slope of double logarithm curve of $\ln \mathrm{V}$ versus $\ln \left(\ln \left(P^{0} / P\right)\right)$.

To date, the pore fractal dimension of a coal sample can be obtained by using formulas (3) and (4) based on the FHH model to calculate LPNA data [20,46]:

$$
\begin{aligned}
& D_{2}=3+3 A, \\
& D_{2}=3+A,
\end{aligned}
$$

where $D_{2}$ is the fractal dimension.

In the low-medium pressure region $\left(P / P^{0}<0.5\right)$, the main force between the pore adsorption interface and $N_{2}$ is Van der Waals force (VDWF). Formula (3) represents the relationship between $D_{2}$ and $A$. In the experimental high-pressure region $(P /$ $P^{0} \geq 0.5$ ), coal pore capillary condensation occurs, the adsorption mechanism changes, and the relationship between $D_{2}$ and A changes synchronously, which meets formula (4). Most of the $D_{2}$ values obtained by formula (3) are less than 2, which violates the geometric meaning of the fractal dimension of coal pores; that is, $D_{2}$ should be between 2 and 3 [37, 52]. Comparatively speaking, $D_{2}$ obtained by formula (4) has practical geometric significance. Therefore, the $\mathrm{FHH}$ fractal dimension of the coal sample pore $(d<100 \mathrm{~nm})$ is uniformly obtained by formula (4) [42].

\section{Results and Discussion}

According to the B.B. Hotdot pore diameter classification system, coal matrix pores can be divided into four categories: micropore (pore diameter $d<10 \mathrm{~nm}$ ), minipore $(10 \mathrm{~nm}<d<100 \mathrm{~nm})$, mesopore $(100 \mathrm{~nm}<d<1000 \mathrm{~nm})$, and macropore $(d>1000 \mathrm{~nm})$ [37]. Among them, minipores and micropores provide the main storage space for gas adsorption, while macropores and mesopores will provide the main paths for gas diffusion and fluid flow $[37,46]$.

3.1. MIP Results for Coal Samples Subject to Different Vibration Frequencies. Figure 3 shows the MIP intrusion and extrusion curves of coal samples with vibration at different frequencies. When the mercury injection pressure is below $0.1 \mathrm{MPa}(D \approx 10000 \mathrm{~nm})$, mercury mainly penetrates the intergranular pores [52], and when the mercury injection pressure is greater than $10 \mathrm{MPa}(D \approx 120 \mathrm{~nm})$, the coal matrix is compressed and this deformation causes pore damage [42]. Therefore, MIP is mainly used to analyze the structural characteristics of mesopores and macropores.

There is an obvious hysteresis loop between the MIP intrusion and extrusion curves of the VDF coal samples. The possible reasons for the formation of the hysteresis loop are the different contact angles between the coal during mercury intrusion and extrusion, and mercury and the existence of an "ink-bottle" hole in coal [49]. Moreover, the hysteresis loop formed by the mercury intrusion and extrusion curves reflects the connectivity of the pore-fracture network structure [34]. Broad hysteresis loops indicate excellent pore connectivity. Compared with the raw coal sample, the hysteresis ring width of $\mathrm{S}_{75}$ is significantly increased, which indicates that the $75 \mathrm{~Hz}$ vibration caused the pore-fracture structure of the coal sample to expand and develop and then promoted the maximum increase of connectivity. Except for $S_{75}$, there is no obvious change to the hysteresis loop width of the coal samples, which indicates that the pore connectivity has had little change.

Figure 3 shows that the total mercury intrusion volume of VDF coal samples first increases and then decreases with an increase in vibration frequencies. At $378.89 \mathrm{MPa}$ high pressure, the maximum mercury intrusion volumes of $\mathrm{S}_{0}$, 


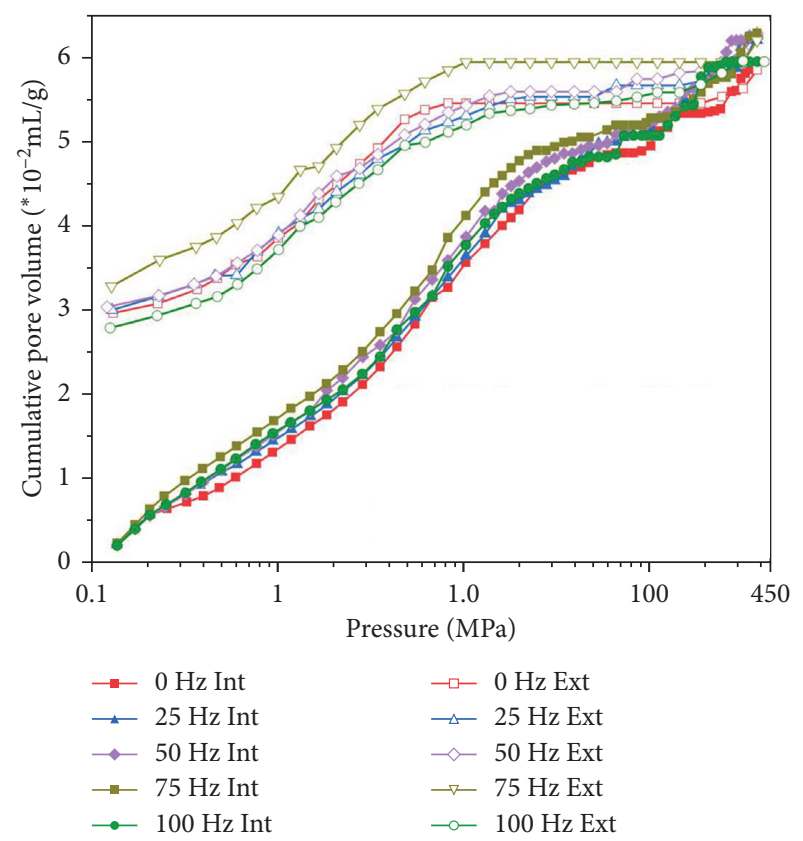

FIGURE 3: MIP intrusion and extrusion curves of the VDF coal samples.

$\mathrm{S}_{25}, \mathrm{~S}_{50}, \mathrm{~S}_{75}$, and $\mathrm{S}_{100}$ were $0.0587 \mathrm{ml} / \mathrm{g}, \quad 0.0621 \mathrm{ml} / \mathrm{g}$, $0.0627 \mathrm{ml} / \mathrm{g}, 0.0629 \mathrm{ml} / \mathrm{g}$, and $0.0596 \mathrm{ml} / \mathrm{g}$, respectively. $\mathrm{S}_{75}$ was the maximum and $\mathrm{S}_{0}$ the minimum volumes. Compared with $\mathrm{S}_{0}, \mathrm{~S}_{75}$ increased the mercury intrusion volume by $7.16 \%$. There are two possible reasons why vibration caused an increase in the mercury injection volume. First, when the amplitude is constant, the greater the frequency, the greater the acceleration and force of the vibration of the coal matrix $[21,22]$. The coal matrix is destroyed and deformed due to mechanical extrusion, which leads to the expansion and development of pores and microcracks. Second, the increase of the vibration frequency makes the number of collisions between coal particles increase, resulting in the expansion and development of microcracks on the surface of coal particles. The reason for the largest pore volume of $S_{75}$ is that the vibration frequency of $75 \mathrm{~Hz}$ is close to the natural frequency of raw coal, and then resonance occurs. For four frequency vibration coal samples, the pore volume of $S_{100}$ is the minimum, which may be due to the destruction and collapse of the skeleton of the coal matrix due to great extrusion stress, and some pore channels are blocked.

Figure 4 shows that the PSD of macropores and mesopores in VDF coal samples first decreases and then increases with the decrease of pore size. With the increase of vibration frequency, the volume of macropores first increases and then decreases, the value of $S_{75}$ is the maximum, and the value of $S_{0}$ is the minimum; the volume of mesopores shows a wavy trend of first decreasing, then increasing, and after that decreasing with the increase in vibration frequencies, the value of $S_{75}$ is the maximum, and the value of $S_{25}$ is the minimum. The variation range of the total volume of the macropores with the vibration frequency is obviously larger than that of the mesopores. Compared with $\mathrm{S}_{0}$, the macropores volume of $\mathrm{S}_{75}$ has the largest increase, up to $25.44 \%$. And compared with $\mathrm{S}_{0}$, the mesopores volume of $\mathrm{S}_{25}$ decreases by $2.33 \%$, and the mesopores volume of $\mathrm{S}_{75}$ increases by $8.78 \%$. The influence of vibration on the total volume of macropores is obviously stronger than that of mesopores, and the impact of the $75 \mathrm{~Hz}$ vibration on the total volume of macropores and mesopores is the most significant. Song et al. [24-26] used CT scanning technology to draw the conclusion that vibration promotes the expansion of coal rock fractures and new fracture development, resulting in a permeability increase. This conclusion also proves the above results, to a certain extent.

With the decrease of pore size, the PSD of all coal samples first decreases and then increases (Figure 4). In the range of $2000 \sim 10000 \mathrm{~nm}$, the pore size distribution of the vibration coal sample is obviously different from that of the raw coal sample. Compared with $\mathrm{S}_{0}$, the pore volumes of $\mathrm{S}_{25}, \mathrm{~S}_{50}, \mathrm{~S}_{75}$, and $\mathrm{S}_{100}$ increased by $14.43 \%, 19.99 \%, 36.36 \%$, and $21.32 \%$, respectively. The results show that vibration leads to the increase of pore size in the range of $2000 \sim 10000 \mathrm{~nm}$; and except for $75 \mathrm{~Hz}$ vibration, the higher the vibration frequency, the more obvious the increase in pore volume. In the range of $800 \sim 2000 \mathrm{~nm}$, the PSD of five coal samples is close, which indicates that the influence of vibration on the pore size is not obvious. Compared with $\mathrm{S}_{0}$, the pore volumes of $\mathrm{S}_{25}, \mathrm{~S}_{50}, \mathrm{~S}_{75}$, and $\mathrm{S}_{100}$ increased by $6.45 \%, 10.47 \%$, and $1.13 \%$, respectively, in the range of $100-800 \mathrm{~nm}$, but the pore volume of $\mathrm{S}_{25}$ decreased by $1.96 \%$. The 25 and $100 \mathrm{~Hz}$ vibrations have little effect on the volume of mesopores in the pore size range of 100 800 nm. The vibration at $75 \mathrm{~Hz}$ has a significant impact on the mesopore volume in this range. And, in this pore size range, with the decrease of pore size, the pore size distribution of the coal samples with different frequencies fluctuates greatly compared with the raw coal samples, showing a single and multipeak distribution. This shows that vibration has a great influence on the pore sizes distribution in this range. The pore size distribution of $S_{50}$ and $\mathrm{S}_{100}$ fluctuated obviously. And compared with $\mathrm{S}_{0}$, the pore volume differential of $S_{50}$ increases significantly at $226.88 \mathrm{~nm}, 433.44 \mathrm{~nm}$, and $676.43 \mathrm{~nm}$, and the pore volume differentiation of $S_{100}$ at $151.08 \mathrm{~nm}$ and $283.81 \mathrm{~nm}$ increases significantly. The pore volume distribution of $S_{75}$ increases uniformly with the decrease of pore size, and the pore volume differential at $151.17 \mathrm{~nm}$ is significantly larger than that of other coal samples. This demonstrates that the effect of resonance on the coal pore structure is more obvious. The PSD of $\mathrm{S}_{25}$ is the most uniform, and there is no large fluctuation. However, the pore size of $\mathrm{S}_{25}$ decreases in the range of $100 \sim 800 \mathrm{~nm}$ due to the $25 \mathrm{~Hz}$ vibration.

There are two reasons for the influence of vibration on the PSD and TPV change of macropores and mesopores in the coal samples. First, the periodic extrusion stress generated by vibration makes the parts of the coal matrix skeleton with weak antiextrusion ability collapse or fracture, and the pore volume decreases due to the collapse of the coal matrix skeleton blocking some of the pores. At the same time, the pore volume increases due to the expansion and development of pore fractures caused by the fracture of the coal matrix skeleton. Secondly, the matrix pores are 


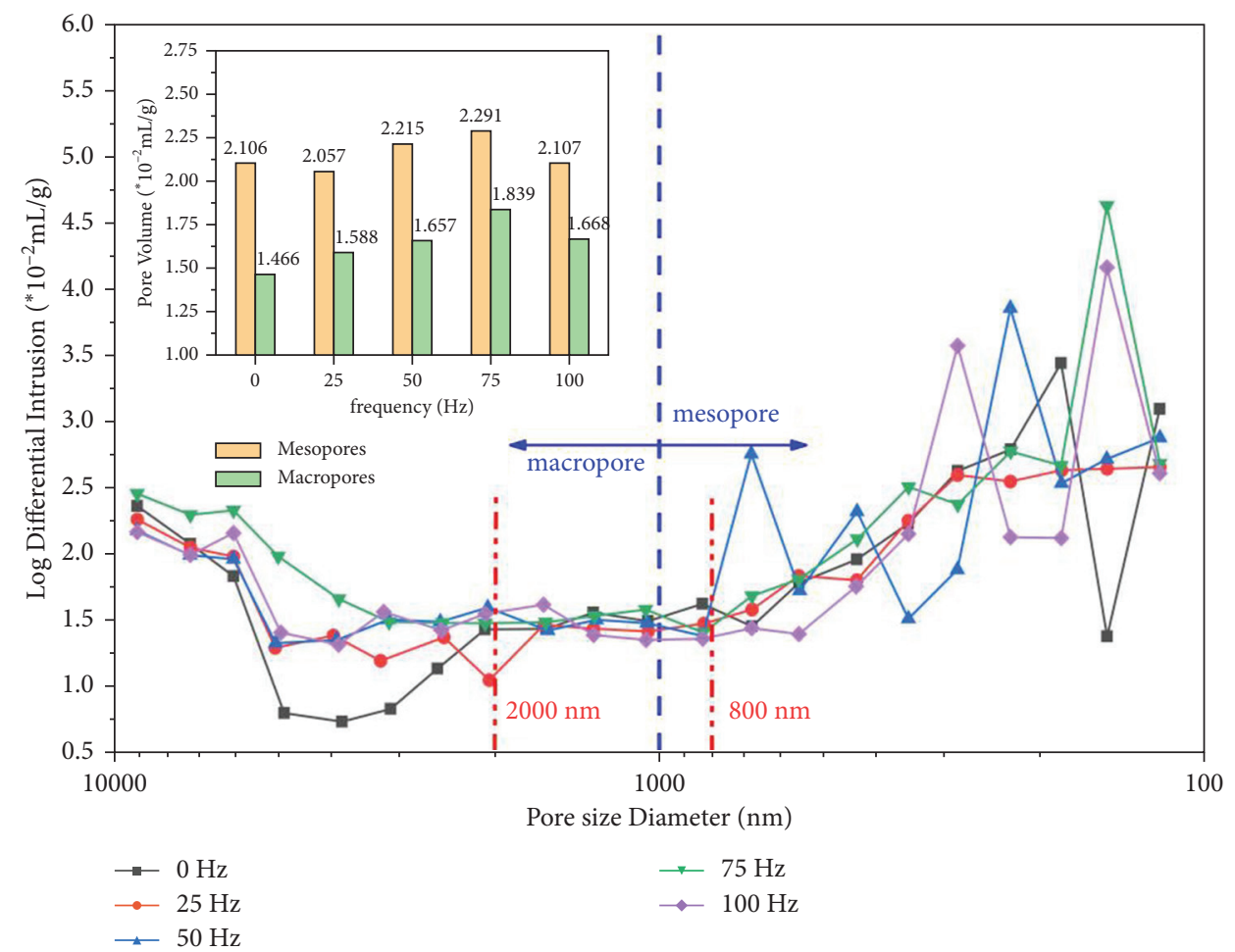

FIgURE 4: PSD and TPV of macropores and mesopores.

extruded due to the deformation of the part of the coal matrix skeleton caused by periodic extrusion stress, resulting in the bulge or depression of pore surfaces. The greater the vibration frequency, the stronger the extrusion pressure of coal matrix [22], and as a result, the possibility of deformation and failure of coal matrix skeleton is greater. When the vibration condition resonates with the natural frequency of the coal sample, the vibration has the strongest effect on the destruction and deformation of the coal matrix skeleton [29]. The change of the coal pore structure caused by vibration is caused by the superposition of the collapse and fracture of coal matrix skeleton and the concave and convex deformation of some areas, which eventually leads to the increase of the pore size of macropores and mesopores and then increases the permeability of coal seam.

The PSD and TPV of coal samples change due to vibration, which inevitably leads to the change of pore SSA. Figure 5 shows the distribution of the macropores and mesopores SSA of the VDF coal samples.

Figure 5 shows that the total SSA of mesopores is much larger than that of macropores. With the increase of vibration frequency, the SSA of mesopores first decreases, then increases, and after that decreases. The SSA of $\mathrm{S}_{25}$ decreased by $1.95 \%$ compared to that of $S_{0}$, while that of $S_{75}$ increased by $13.16 \%$ compared to that of $S_{0}$. The SSA of macropores first increased and then decreased with the increase of vibration frequency. Compared with $S_{0}$, the total specific surface area of macropores of $S_{75}$ changed the most, reaching $16.72 \%$. From the perspective of variation quantity, the influence of vibration on the SSA of macropores is greater than that of mesopores. The above results are consistent with the variation trend of the total volume of macropores and mesopores in Figure 4. Because the pore volume increases, the corresponding pore specific surface area increases.

The pore SSA distribution in Figure 5 shows that the pore specific surface area differential of all coal samples increases with the decrease of pore diameter. The differential growth of the specific surface area of macropores was slow, and the value of the specific surface area was between 0 and $0.01 \mathrm{~m}^{2} / \mathrm{g}$. The specific surface area of mesopores differential growth is rapid; the SSA of $S_{25}$ in the region increases evenly; and $S_{50}, S_{75}$, and $S_{100}$ in the process of increasing the region show varying degrees of fluctuation. The fluctuation range of pore specific surface area distribution of all coal samples is basically consistent with that in Figure 4. Vibration results in the change of pore volume and pore surface morphology. The deformation and destruction of the coal matrix skeleton result in pore convex deformation or collapse, changing the size of the specific surface area. In addition, vibration may lead to the stripping or peeling of minerals attached to the pore surface, resulting in changes in the specific surface area.

The influence of vibration on TPV, SSA, and PSD of macropores and mesopores in coal samples will inevitably lead to the change of surface morphology characteristics of pores and fissures. Fractal geometry is a powerful quantitative expression method, so the fractal dimension is used to quantitatively characterize its surface morphology. The fractal dimensions of macropores and mesopores were defined as $D_{11}$ and $D_{12}$, respectively, as shown in Figure 9. 


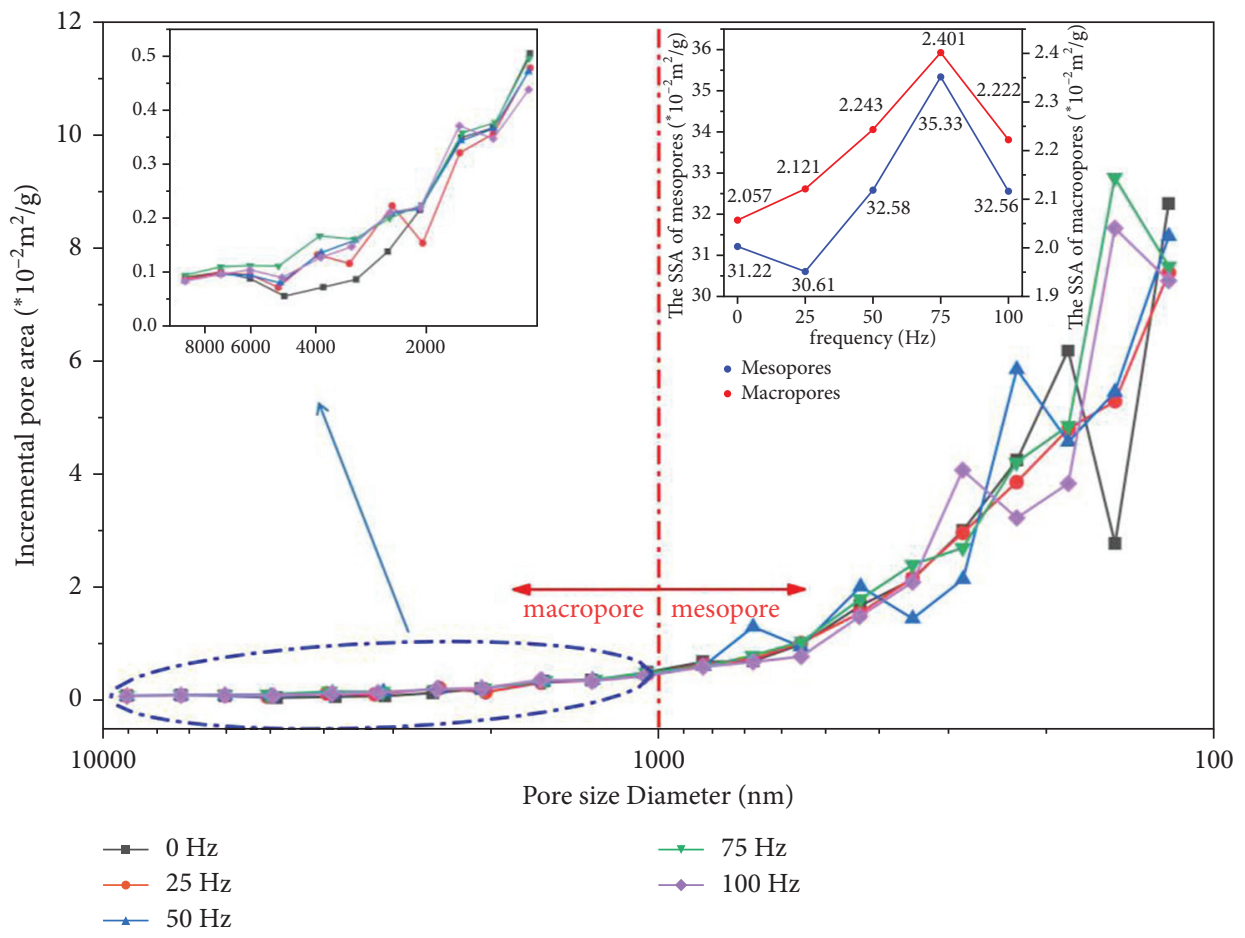

FIGURE 5: The SSA distribution of macropores and mesopores.

3.2. LPNA Results for Different Vibration Frequency Coal Samples. The pore measurement range of LPNA is $1.3 \sim 300 \mathrm{~nm}$, which is commonly used to analyze the micropores and minipores $[20,34,42]$. The adsorption and desorption isotherm of VDF coal samples are similar in shape and have hysteresis loops (Figure 6). According to the IUPAC classification of hysteresis loops [40], the hysteresis loops of all coal samples fall into the $\mathrm{H} 3$ type, indicating that there are slit-like pores in the coal samples.

When the relative pressure is $0<P / P^{0}<0.45$, the adsorption isotherm increases slowly (Figure 6), indicating that monolayer and multilayer adsorption are formed in micropores and minipores. When the relative pressure is $0.45<P / P^{0}<1$, the adsorption capacity of gas molecules is enhanced due to capillary condensation. Figure 6(d) shows that the $S_{75}$ coal sample presents obvious hysteresis loops under low relative pressure, which may be due to the irreversible absorption of gas molecules and irreversible chemical reaction between gas and pore surface, or due to the existence of some open holes (including cylindrical pores with both ends open and flat pores with four sides parallel) or ink-bottle pores in $S_{75}$ [53]. The $75 \mathrm{~Hz}$ vibration leads to an increase in the number of open pores in coal samples.

Figure 6 shows that the adsorption and desorption isotherms of all coal samples are divided into two regions with $P / P^{0} \approx 0.45$ as the dividing point, indicating that the adsorption mechanism of these two regions is different. Therefore, in the analysis of fractal dimensions, the adsorption and desorption isotherms should be divided into two regions: $0<P / P^{0}<0.45$ and $0.45<P / P^{0}<1$, and the fractal dimensions of the two regions are defined as $D_{21}$ and $D_{22}$, respectively. The DFT method is a powerful tool for obtaining the distribution characteristics of micropores and minipores by using the LPNA data [20,49]. To explore the influence of vibration with different frequencies on the TPV and SSA of micropores and minipores in coal samples, the PSD and pore SSA distribution of $1.3 \sim 100 \mathrm{~nm}$ is plotted, as shown in Figures 7 and 8.

Figure 7 shows that the pore volumes of $S_{0}, S_{25}, S_{50}, S_{75}$, and $S_{100}$ are dominated by minipores, which are also reflected in the pore volume distribution curves of minipores and micropores. Compared with $\mathrm{S}_{0}$, the minipores volume of $\mathrm{S}_{25}$ decreased most significantly, reaching $13.71 \%$. The minipores volume of $S_{50}$ is slightly lower than that of $S_{0}$. However, compared with $S_{0}$, the minipores volume of $S_{75}$ and $S_{100}$ are not significantly changed. Compared with $S_{0}$, the micropores volume of $S_{75}$ increased by $157 \%$, and that of $\mathrm{S}_{25}$ decreased by $10.21 \%$. The results show that a $75 \mathrm{~Hz}$ vibration has the obvious effect of expanding micropores, the pore size increases, and the gas adsorption space increases, while a $25 \mathrm{~Hz}$ vibration leads to the decrease of micropore volume and gas adsorption space. The effect of vibration on micropores is greater than that on minipores. The $25 \mathrm{~Hz}$ low-frequency vibration produces smaller extrusion stress, and the deformation and destruction of coal matrix skeleton mainly lead to pore extrusion and plugging and a reduced pore volume; the $75 \mathrm{~Hz}$ vibration resonates with the coal matrix, which leads to the severe deformation and destruction of coal matrix skeleton and promotes the expansion and development of micropores.

With the decrease of pore size, the pore volume distribution curve of five coal samples in the range of $1.3 \sim 100 \mathrm{~nm}$ first decreases, then increases, and after that decreases. With the decrease of pore size, the PSD of $S_{0}, S_{50}$, 


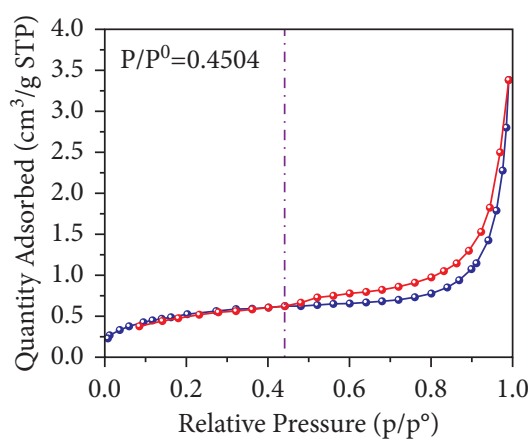

$0 \mathrm{~Hz}$

$\because$ Adsorption

$\because$ Desorption

(a)

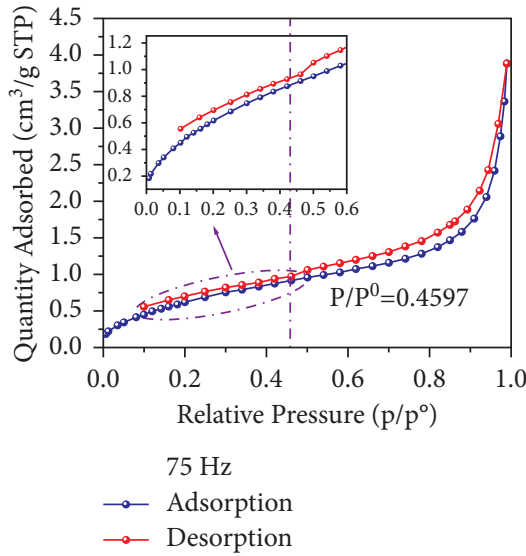

(d)

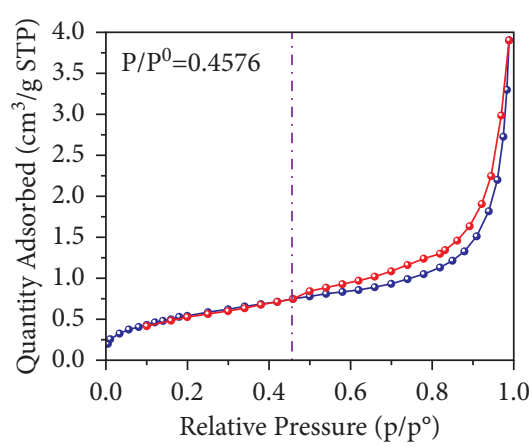

$25 \mathrm{~Hz}$

$\rightarrow$ Adsorption

- Desorption

(b)

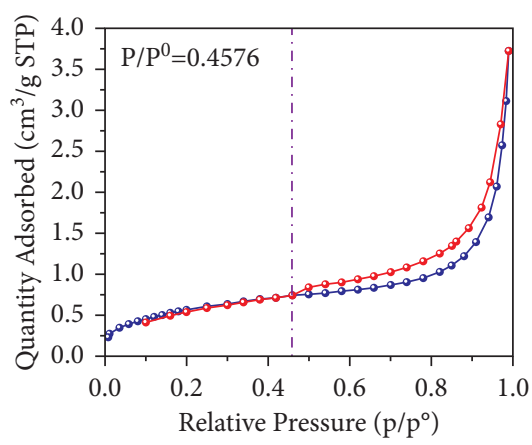

$50 \mathrm{~Hz}$

$\because$ Adsorption

$\because$ Desorption

(c)

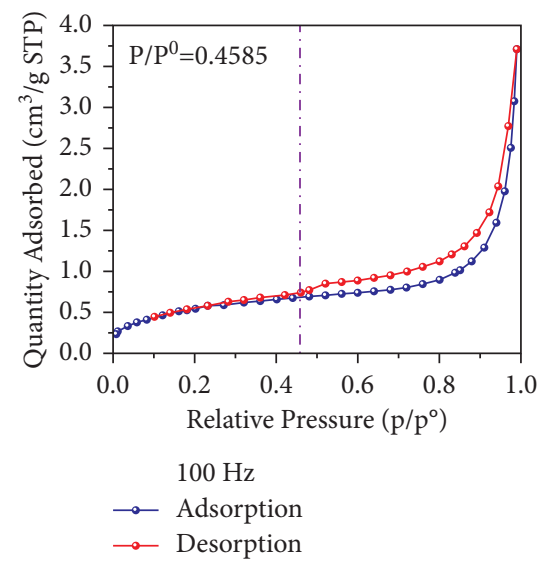

(e)

FIGURE 6: LPNA adsorption and desorption isotherms in the VDF coal samples.

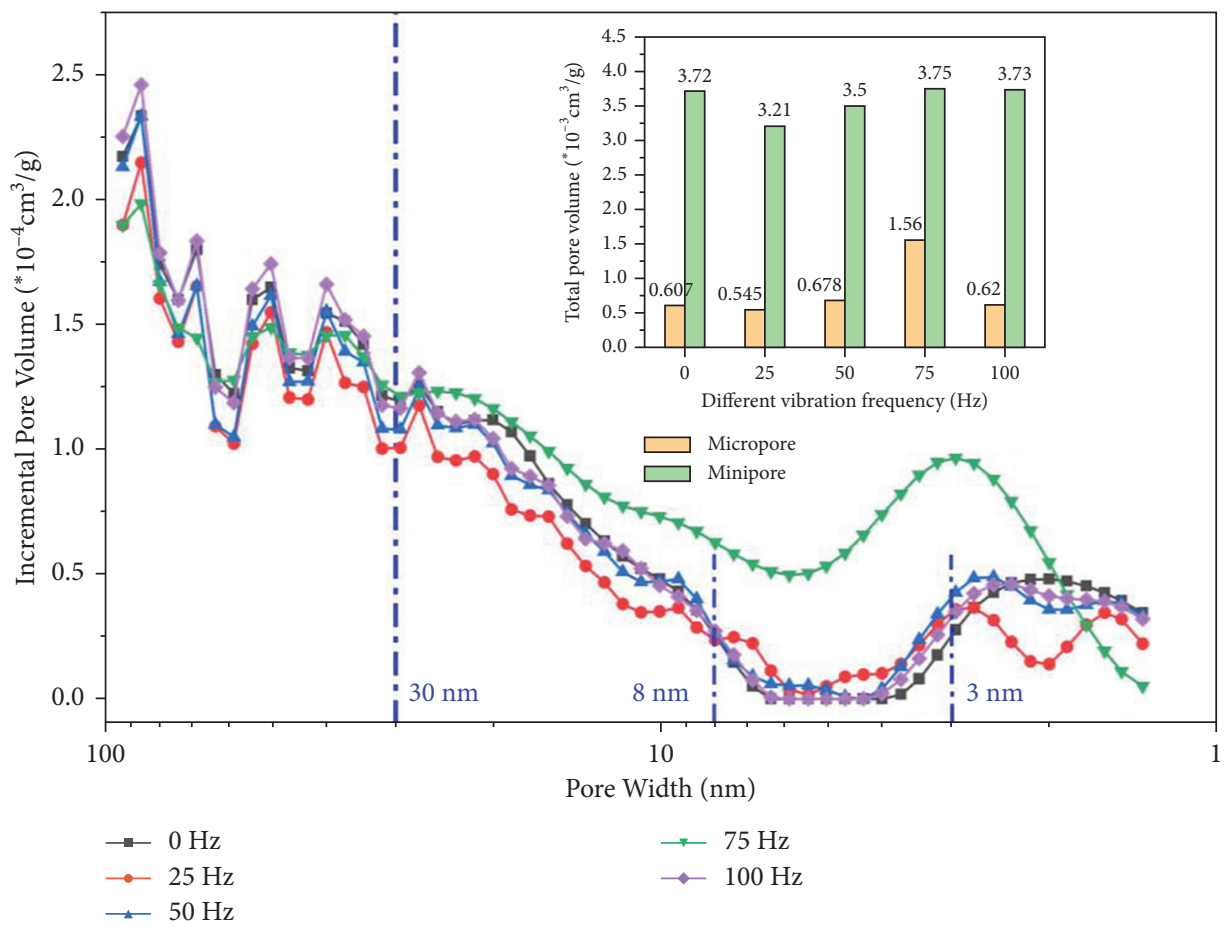

Figure 7: Pore size distribution of micropores and minipores. 


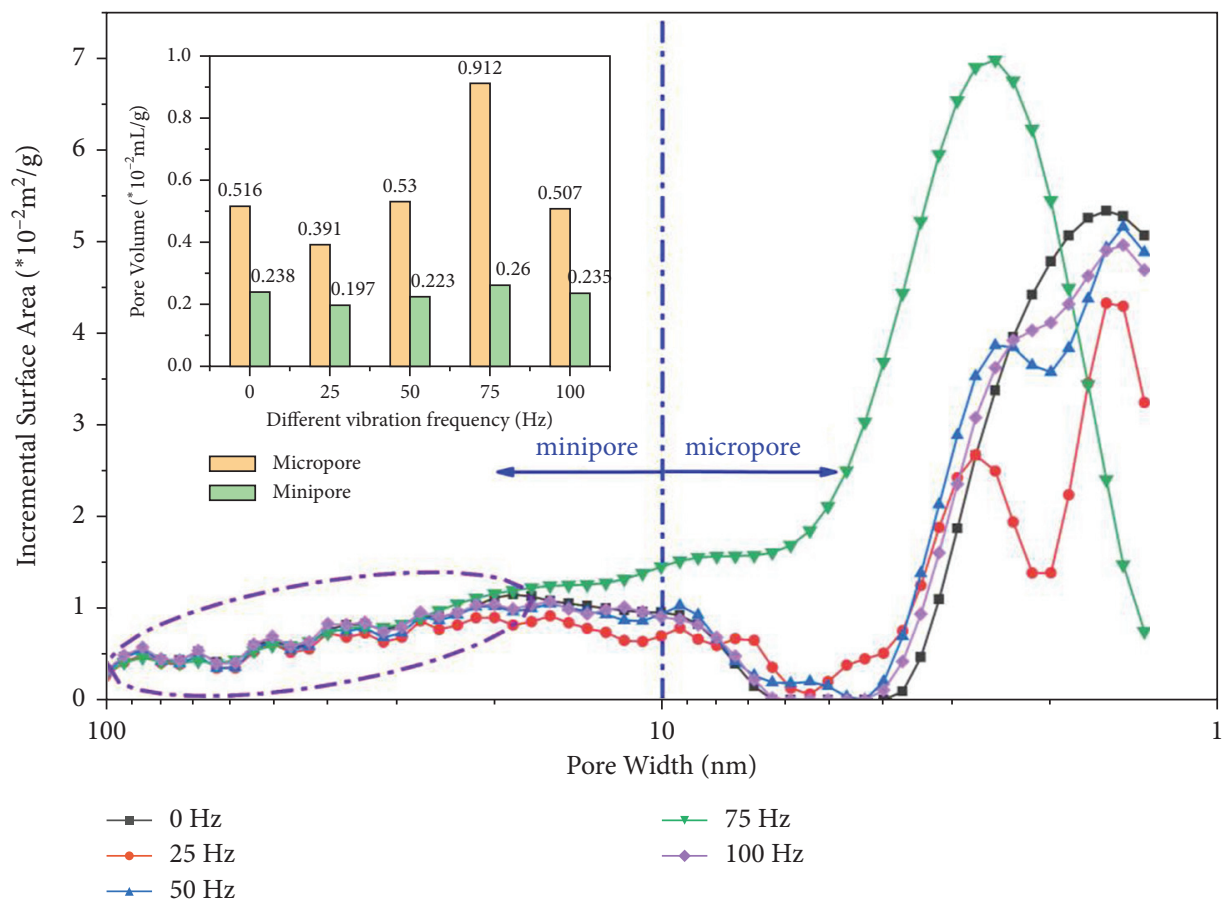

FIGURE 8: Distribution of the specific surface area of minipores and micropores.

and $S_{100}$ are similar, which indicates that there is little influence of 50 and $100 \mathrm{~Hz}$ vibrations on the PSD of micropores and pores. However, the PSD of $S_{25}$ and $S_{75}$ are obviously different from other coal samples, which indicates that 25 and $75 \mathrm{~Hz}$ have a great influence on the PSD. In the range of $8 \sim 100 \mathrm{~nm}$ and $1.3 \sim 3 \mathrm{~nm}$, the pore volume differential of $S_{25}$ is obviously smaller than that of other coal samples, which indicates that the pore volume and pore size of $S_{25}$ decrease under the vibration of $25 \mathrm{~Hz}$. However, when the pore size is in the range of $1.3 \sim 30 \mathrm{~nm}$, the pore volume differential of $\mathrm{S}_{75}$ is significantly larger than that of other coal samples, which indicates that a $75 \mathrm{~Hz}$ vibration leads to the increase of pore size and the expansion effect is obvious. The reasons may be as follows: first, the $75 \mathrm{~Hz}$ vibration resonates with the coal matrix, resulting in the serious deformation and damage of the coal matrix skeleton so that some of the pores with small pore sizes develop and expand into pores with larger pore sizes, while the vibration of $25 \mathrm{~Hz}$ mainly causes deformation of coal matrix, thus squeezing small holes and micropores. The above results show that the volume and pore sizes decrease significantly when the vibration frequency is $25 \mathrm{~Hz}$, but both the pore size and volume increase at the vibration of $75 \mathrm{~Hz}$.

Figure 8 shows that the pore $(1.3 \sim 100 \mathrm{~nm})$ SSA of the VDF coal sample is dominated by micropores. With the increase of frequency, the total SSA of minipores and micropores first decreases, then increases, and after that decreases. The total minipores SSA of $S_{25}, S_{50}$, and $S_{100}$ decreased by $17.23 \%, 6.30 \%$, and $1.26 \%$, respectively, compared with $S_{0}$, while that of $S_{75}$ increased by $9.24 \%$. Compared with $\mathrm{S}_{0}$, the total micropores SSA of $\mathrm{S}_{75}$ and $\mathrm{S}_{50}$ increased by $76.74 \%$ and $2.71 \%$, respectively, while that of $S_{100}$ and $S_{25}$ decreased by $2.71 \%$ and $24.22 \%$, respectively.
The $25 \mathrm{~Hz}$ vibration significantly reduces the total SSA of micropores and minipores, while the vibration frequency of $75 \mathrm{~Hz}$ significantly increases the total SSA of micropores and minipores.

It can be seen from the SSA distribution curve that the minipore SSA of all coal samples is roughly distributed in the range of $0.003 \sim 0.015 \mathrm{~m}^{2} / \mathrm{g}$ with the decrease of pore size, and the change is not obvious (Figure 8). The minipores SSA distribution of $S_{0}, S_{25}, S_{50}$, and $S_{100}$ first increases slowly and then decreases slightly with the decrease of pore size; the minipores SSA distribution of $S_{75}$ gradually increases with the decrease of pore diameter. However, the SSA differential of micropores decreases and then increases as the pore size decreases. The micropores SSA distribution of $S_{25}$ and $S_{75}$ is obviously different from other coal samples. The micropores SSA distribution of $S_{75}$ increases slowly and then rapidly with the decrease of pore size and then decreases rapidly after reaching a peak value at about $2.5 \mathrm{~nm}$. Moreover, the SSA differential of $S_{75}$ in the range of $2 \sim 10 \mathrm{~nm}$ is obviously larger than that of other coal samples. The SSA differential of $S_{25}$ in the range of $3 \sim 10 \mathrm{~nm}$ is close to that of $S_{0}, S_{50}$, and $S_{100}$, but there is no obvious change. However, in the range of $1.3 \sim 3 \mathrm{~nm}$, the SSA differential of $S_{25}$ is significantly lower than that of other coal samples.

According to the above results, we can conclude that the effect of vibration on micropores is greater than that on minipores. Among them, a $75 \mathrm{~Hz}$ vibration significantly increases the TPV and SSA of micropores, resulting in the increase of gas adsorption space. However, the TPV and SSA of minipores and micropores as gas storage space decrease due to a $25 \mathrm{~Hz}$ vibration which, to a certain extent, explains the reason why low-frequency vibrations inhibit gas adsorption [7]. 

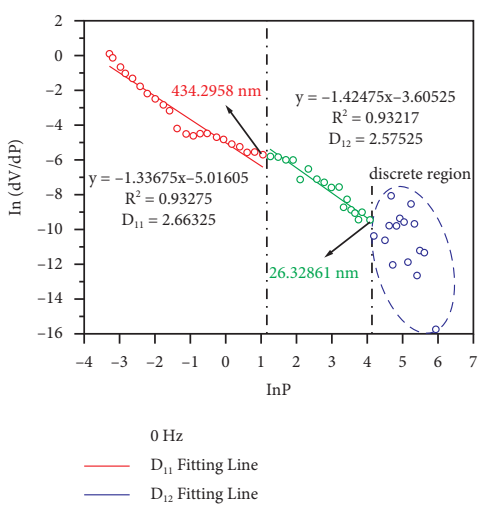

(a)

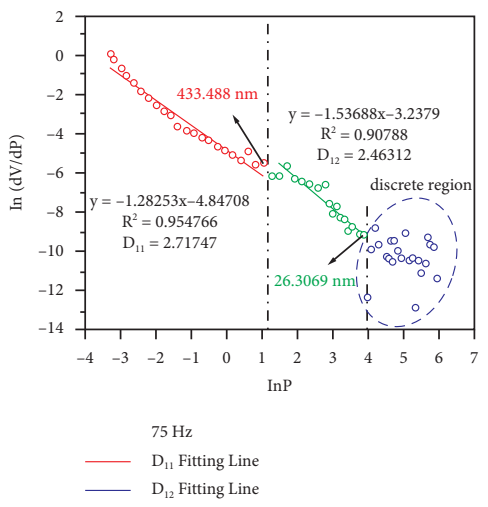

(d)

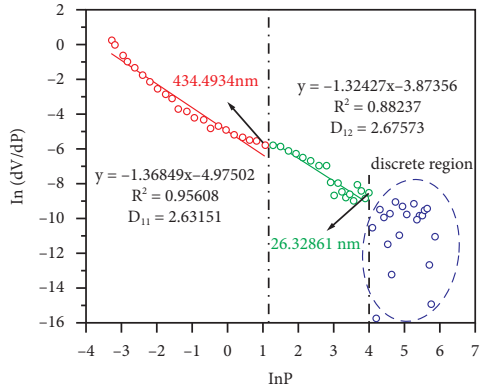

$25 \mathrm{~Hz}$

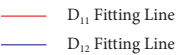

(b)

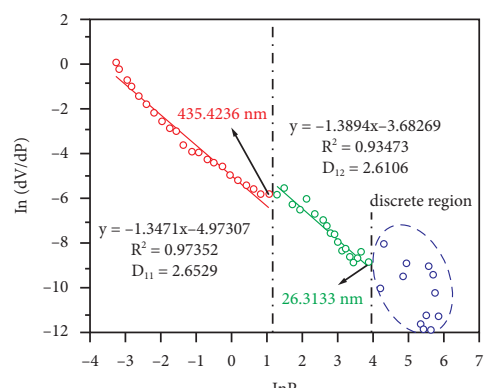

$\mathrm{InP}$

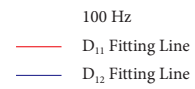

(e)

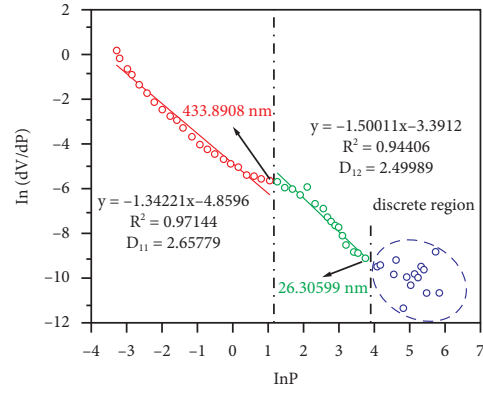

$50 \mathrm{~Hz}$

$\mathrm{D}_{11}$ Fitting Line

$-\mathrm{D}_{12}$ Fitting Line

(c)

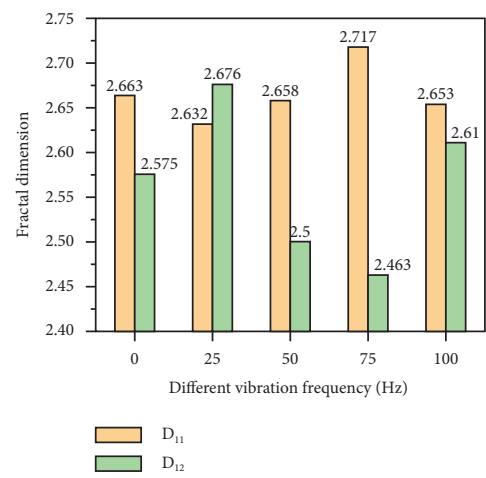

(f)

FIGURE 9: Fractal dimension of macropores and mesopores of the VDF coal samples: (a-e) the fractal characteristics of the macropores and mesopores at $0,25,50,75$, and $100 \mathrm{~Hz}$ vibration-based MIP data, respectively; (f) fractal trend of $D_{11}$ and $D_{12}$.

\subsection{Fractal Dimensions of Pores and Fissures in the VDF Coal} Samples. Based on the MIP and LPNA data, the fractal dimensions $D_{11}, D_{12}$ and $D_{21}, D_{22}$ were calculated by formulas (1) and (4), respectively. The larger the fractal dimension, the more complex and rougher the pore structure and the pore surface $[20,39,42,43]$.

3.3.1. Fractal Dimensions of Mesopores and Macropores Based on MIP. Figures 9(a)-9(e) show that the fractal dimensions $D_{11}$ and $D_{12}$ have good fitting, with $R^{2}$ values of $0.93275 \sim 0.97352$ and $0.88237 \sim 0.94406$, respectively. The pore structure of the VDF coal samples in the test range has significant fractal characteristics. The fractal curve of the MIP data of all the coal samples is obviously divided into three parts by two points: one point is near $\ln \mathrm{P}=1$ and the corresponding pore size range is about $433.4 \sim 435.4 \mathrm{~nm}$; the other point is near $\ln \mathrm{P}=4$ and the corresponding pore size range is about $26.31 \sim 26.33 \mathrm{~nm}$. When $\ln \mathrm{P}>4$, the mercury injection data are discrete, which may be due to the high mercury intrusion pressure resulting in coal matrix deformation and pore failure. And the pressure of the highpressure mercury injection measured by MIP will compress the pore matrix, which will cause errors in the experimental results. Therefore, the data of the high-pressure section cannot be used to obtain the fractal dimensions [34].
3.3.2. Fractal Dimension of Minipores and Micropores Based on the LPNA Results. Figures 10(a)-10(e) show that the fractal dimensions $D_{21}$ and $D_{22}$ have good fitting, with $R^{2}$ values being $0.97739 \sim 0.99852$ and $0.94367 \sim 0.97162$, respectively. The pore structure of the VDF coal samples has obvious fractal characteristics in the whole range of relative pressure measurement. All the coal samples had fractal curves of LPNA that are divided into two regions about ln $\left.\left(\ln \mathrm{P} / \mathrm{P}^{0}\right)\right)=-0.225\left(\mathrm{P} / \mathrm{P}^{0}=0.45\right)$, and the corresponding turning point pore size is in the range of $3.52 \sim 3.69 \mathrm{~nm}$.

It can be seen from Figure 10(f) that, with the increase of vibration frequency, $D_{21}$ presents an "M" shaped wave-like trend, which first increases, then decreases, after increases, and finally decreases, while $D_{22}$ presents a "W" wave-like trend opposite to $D_{21}$. The value of $D_{21}$ fluctuates in a small range of 2.589 2.663, the $D_{21}$ value of $S_{0}$ is the smallest, and the $D_{21}$ value of $S_{75}$ is the largest. It indicates that vibration causes the surface morphology of pores $(3.5 \sim 100 \mathrm{~nm})$ to be complicated but has little effect. The values of $D_{22}$ fluctuate in a wide range from 2.106 to 2.473 , the $D_{22}$ value of $S_{75}$ is the smallest, and the $D_{22}$ value of $S_{0}$ is the largest; it indicates that vibration causes the surface of micropores with pore size less than $3.5 \mathrm{~nm}$ to be smoother, and 25 and $75 \mathrm{~Hz}$ vibrations can greatly damage the surface morphology of micropores with pore sizes less than $3.5 \mathrm{~nm}$. The variation range of $D_{21}$ is obviously smaller than that of $D_{22}$, indicating that vibration 


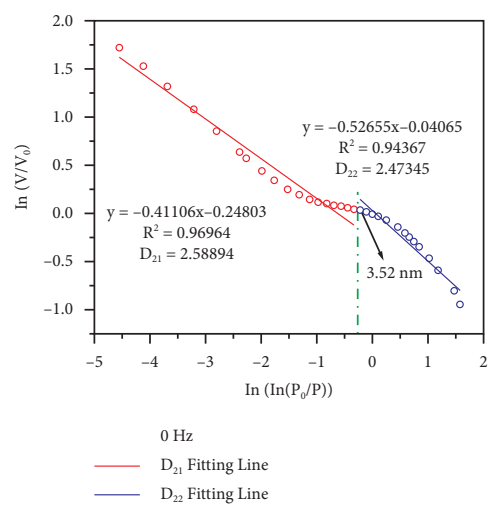

(a)

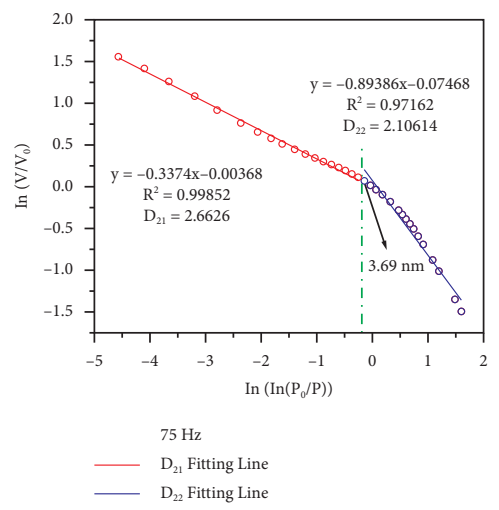

(d)

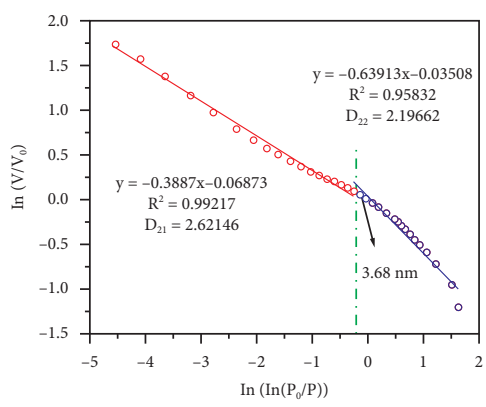

$25 \mathrm{~Hz}$

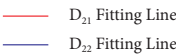

(b)

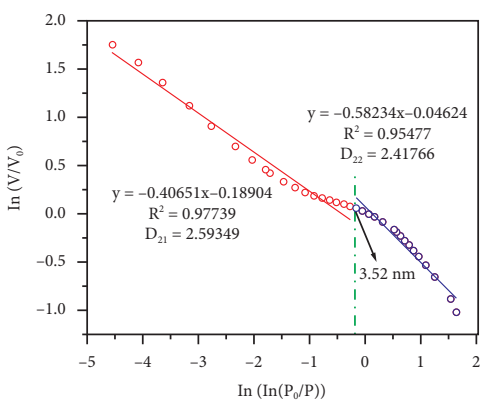

$100 \mathrm{~Hz}$

$\mathrm{D}_{21}$ Fitting Line

- $\mathrm{D}_{22}$ Fitting Line

(e)

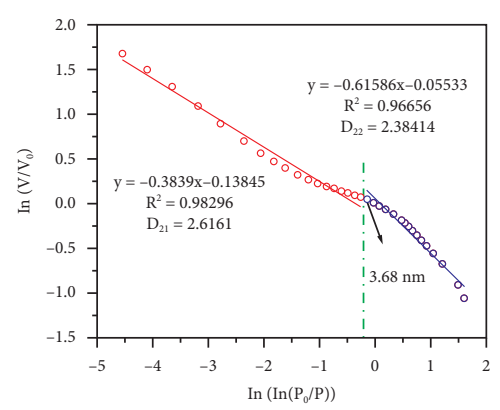

$50 \mathrm{~Hz}$

$\mathrm{D}_{21}$ Fitting Line

- $\mathrm{D}_{22}$ Fitting Line

(c)

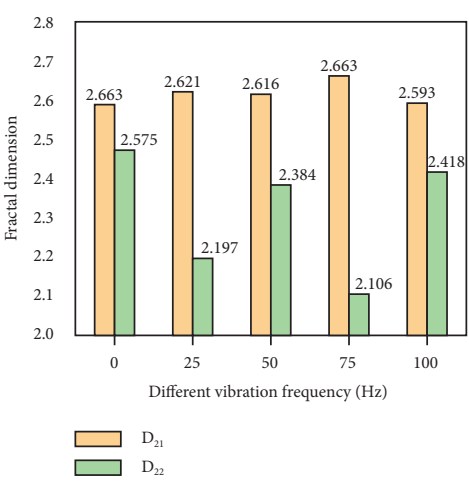

(f)

FIGURE 10: Fractal dimension of micropores and minipores of the VDF coal samples: (a-e) the fractal characteristics of the micropores and minipores at $0,25,50,75$, and $100 \mathrm{~Hz}$ vibration-based LPNA data, respectively; (f) fractal trend of $D_{21}$ and $D_{22}$.

has a more significant effect on the surface morphology complexity of micropores with pore size less than $3.5 \mathrm{~nm}$.

There are three main reasons for the destruction of pore surface morphology characteristics caused by vibration: first, the coal matrix deformation caused by vibration will lead to the concave-convex deformation of the pore surface in a different pore size range; second, the coal matrix damage caused by vibration will cause pore development and expansion in a different pore size range; and third, vibration leads to the loosening, peeling, and shedding of minerals attached to the pore surfaces.

\subsection{Analysis of the Influence on Gas Diffusion and Flow in VDF} Coal Samples with Pore Structure Change. The $75 \mathrm{~Hz}$ vibration increases the TPV and SSA of micropores and minipores, so the adsorption and diffusion space of gas increases, and the gas concentration on the pore surface increases, which is conducive to the migration of gas along the pore wall towards the mesopores and macropores. In addition, the increase of $D_{21}$ also indicates that the diffusion paths and their surfaces are more complicated, and the number of diffusion paths increases. With the increase of the TPV and SSA of macropores and mesopores, the diameter and number of paths for gas diffusions to escape into the outside environment increase, which is conducive to gas diffusion and flow to the outside environment. The increase of the $D_{11}$ value indicates that the macropores and their surfaces are more complex, the paths for gas diffusion are increased, and pore connectivity is enhanced. The decrease of the $D_{12}$ value indicates that surfaces of mesopores are smoother, the way is straighter, and the resistance to gas flowing to the macropores is reduced. Therefore, the $75 \mathrm{~Hz}$ vibration is conducive to the production of gas in the coal seam and contributes to an increased gas extraction rate and the prevention of coal and gas outbursts.

The $25 \mathrm{~Hz}$ vibration leads to the decrease of TPV and SSA of minipores and micropores, the decrease of gas adsorption and diffusion space, and the decrease of gas concentration on pore surfaces, which is not conducive to gas diffusion. With the increase of the macropores' TPV and SSA, the free gas is easily formed by a larger desorption initial velocity. The decrease of the mesopores' TPV and SSA means that the flow paths of gas to macropores are reduced and the paths are narrowed, which is not conducive to the diffusion of gas to macropores and the outside environment. The increase of the $D_{12}$ value also indicates that the complexity of the mesopores increases and the flow path of gas to the macropores is more tortuous. The resistance of free gas in the flow from minipores to mesopores is large, which easily accumulates in large amounts in a short time, resulting in the increase of local gas pressure and concentration. 
Therefore, the $25 \mathrm{~Hz}$ low-frequency vibration is not conducive to the diffusion and flow of gas, which easily leads to local area gas accumulations in the coal, with the risk of inducing local area coal and gas outburst.

\section{Conclusions}

In this paper, the lean coal in the outburst coal seam is taken as the research object, and five vibration frequencies $(0,25$, 50,75 , and $100 \mathrm{~Hz}$, respectively) are selected. Based on MIP and LPNA data, the Menger and FHH models are used to quantitatively characterize the fractal characteristics of the pore surface morphology, and the fractal dimensions were recorded as $D_{11}, D_{12}$ and $D_{21}, D_{22}$, respectively. The conclusions are as follows:

(1) The total pore volume of each vibration coal sample is more than that of the non-Ivibration coal sample. The effect of vibration on the total pore volume and the total specific surface area of macropores is stronger than that of mesopores. And vibration makes the pore size distribution of mesopores more complicated. The $75 \mathrm{~Hz}$ vibration improves the pore connectivity and increases the volume and specific surface area of macropores and mesopores in coal samples significantly.

(2) The pore volume, specific surface area, and pore size distribution of micropores and minipores are significantly affected by 25 and $75 \mathrm{~Hz}$ vibrations. The total volume and specific surface area of minipores and micropores decreased when the vibration frequency was $25 \mathrm{~Hz}$. The $75 \mathrm{~Hz}$ vibration mainly resulted in the increase of micropore volume and specific surface area and the increase of gas adsorption space.

(3) Vibration leads to the change of fractal dimension of pores in coal, and the complexity of the pores in coal with a pore size of $26 \sim 433 \mathrm{~nm}$ and less than $3.5 \mathrm{~nm}$ changes significantly. Among them, the 25 and $75 \mathrm{~Hz}$ vibrations had the most obvious influence on the surface characteristics of coal pores.

(4) The changes of pore structure in coal caused by vibration lead to the path and flow resistance of gas diffusion and flow change. In the study of this paper, the $75 \mathrm{~Hz}$ vibration increases the path of gas diffusion and flow, reduces the flow resistance, and is conducive to the diffusion and flow of gas in coal. But the $25 \mathrm{~Hz}$ low-frequency vibration increases the diffusion resistance of gas and leads to the narrowing and more tortuous flow path of the gas.

\section{Data Availability}

The data used to support the findings of this study are available from the corresponding author upon request.

\section{Conflicts of Interest}

The authors declare that there are no conflicts of interest regarding the publication of this paper.

\section{Acknowledgments}

The authors are grateful to the financial support from the National Natural Science Foundation of China (51574124). They thank TopEdit (http://www.topeditsci.com) for its linguistic assistance during the preparation of this manuscript.

\section{References}

[1] S. A. Shepeleva and V. V. Dyrdin, "Gas emission under coal and gas outbursts," Journal of Mining Science, vol. 47, no. 5, pp. 660-663, 2011.

[2] J. Cao, L. Dai, H. Sun et al., "Experimental study of the impact of gas adsorption on coal and gas outburst dynamic effects," Process Safety and Environmental Protection, vol. 128, pp. 158-166, 2019.

[3] K. Jin, Y. Cheng, T. Ren et al., "Experimental investigation on the formation and transport mechanism of outburst coal-gas flow: implications for the role of gas desorption in the development stage of outburst," International Journal of Coal Geology, vol. 194, pp. 45-58, 2018.

[4] C. Cai and Y. Wang, "Qualitative and quantitative analysis of general regularity of coal and gas outburst," China Safety Science Journal, vol. 14, no. 6, pp. 112-115, 2004.

[5] X. Li, B. Nie, and X. He, "Mechanism of coal and gas bursts caused by vibration," Journal of University of Science and Technology Beijing, vol. 33, no. 2, pp. 149-152, 2011.

[6] Y. Zhao, Experimental Studies on Absorption and Desorption under Low Vibration Environment, Xi'an University of Science and Technology, Xi'an, China, 2011.

[7] S. Li, Y. Zhao, and T. Zhang, "Adsorption properties of coal in the presence of low-frequency mechanical vibration," Journal of China University of Mining \& Technology, vol. 41, no. 6, pp. 873-877, 2012.

[8] X. Sun, The Research on Failure Characteristics and DisasterCausing Mechanism of the Loaded Coal in Vibration, China University of Mining and Technology, Beijing, China, 2016.

[9] Y.-k. Ma, B.-s. Nie, X.-q. He, X.-c. Li, J.-q. Meng, and D.-z. Song, "Mechanism investigation on coal and gas outburst: an overview," International Journal of Minerals, Metallurgy and Materials, vol. 27, no. 7, pp. 872-887, 2020.

[10] B. Yu, Mechanism Of Coal and Gas Outburst China Coal Industry, Publishing House, Beijing, China, 1985.

[11] K. T. Lim and K. Aziz, "Matrix-fracture transfer shape factors for dual-porosity simulators," Journal of Petroleum Science and Engineering, vol. 13, no. 3, pp. 169-178, 1995.

[12] Z. Pan, L. D. Connell, and M. Camilleri, "Laboratory characterisation of coal reservoir permeability for primary and enhanced coalbed methane recovery," International Journal of Coal Geology, vol. 82, no. 3, pp. 252-261, 2010.

[13] Y. Cai, D. Liu, Z. Pan, Y. Yao, J. Li, and Y. Qiu, "Pore structure and its impact on $\mathrm{CH} 4$ adsorption capacity and flow capability of bituminous and subbituminous coals from Northeast China," Fuel, vol. 103, pp. 258-268, 2013.

[14] J. Jiang, Q. Zhang, Y. Cheng, K. Jin, W. Zhao, and H. Guo, "Influence of thermal metamorphism on CBM reservoir characteristics of low-rank bituminous coal," Journal of Natural Gas Science and Engineering, vol. 36, pp. 916-930, 2016.

[15] W. Zhao, Y. Cheng, M. Yuan, and F. An, "Effect of adsorption contact time on coking coal particle desorption characteristics," Energy \& Fuels, vol. 28, no. 4, pp. 2287-2296, 2014. 
[16] G. Cheng, B. Jiang, M. Li, F. Li, and Y. Song, "Effects of porefracture structure of ductile tectonically deformed coals on their permeability: an experimental study based on raw coal cores," Journal of Petroleum Science and Engineering, vol. 193, Article ID 107371, 2020.

[17] Z. Li, D. Liu, Y. Cai, Y. Wang, and J. Teng, "Adsorption pore structure and its fractal characteristics of coals by N2 adsorption/desorption and FESEM image analyses," Fuel, vol. 257, Article ID 116031, 2019.

[18] M. A. A. Ahamed, M. S. A. Perera, S. K. Matthai, P. G. Ranjith, and L. Dong-yin, "Coal composition and structural variation with rank and its influence on the coal-moisture interactions under coal seam temperature conditions-a review article," Journal of Petroleum Science and Engineering, vol. 180, pp. 901-917, 2019.

[19] Y. Zhao, Y. Sun, S. Liu, Z. Chen, and L. Yuan, "Pore structure characterization of coal by synchrotron radiation nano-CT," Fuel, vol. 215, pp. 102-110, 2018.

[20] Z. Li, B. Lin, Y. Gao, Z. Cao, Y. Cheng, and J. Yu, "Fractal analysis of pore characteristics and their impacts on methane adsorption of coals from Northern China," International Journal of Oil, Gas and Coal Technology, vol. 10, no. 3, pp. 306-324, 2015.

[21] S. Li, Y. Zhao, T. Zhang, and H. Xu, "Influence of low-frequency vibration on desorption characteristics of coal sample," Chinese Journal of Rock Mechanics and Engineering, vol. 29, no. S2, pp. 3562-3568, 2010.

[22] S. Li, Y. Zhao, and M. Xu, "Gas porosity formula under low frequency vibration and its testing analysis," Journal of China Coal Society, vol. 41, no. 10, pp. 2612-2619, 2016.

[23] X. X. Chen, L. Zhang, and M. L. Shen, "Experimental research on desorption characteristics of gas-bearing coal subjected to mechanical vibration," Energy Exploration \& Exploitation, vol. 38, 2020.

[24] Y. Song, B. Wu, and B. Zhu, "Study on the permeability of gas-bearing coal under mechanical vibration," Mining Safety \& Environmental Protection, vol. 45, no. 1, pp. 6-10+15, 2018.

[25] Y. Song, Z. Li, D. Cui, Z. Dong, and Y. Li, "Low-frequency vibration permeability characteristics of coal and rock and analysis of loaded fracture process," Journal of Liaoning Technical University, vol. 38, no. 4, pp. 295-300, 2019.

[26] Y. Song, Z. Li, Y. Li, and C. Wang, "Permeability characteristics and Meso-fractures test of coal and rock under the influence of low frequency vibration," Journal of Liaoning Technical University, vol. 38, no. 5, pp. 390-395, 2019.

[27] B. Li, The Seepage experiment of Coal under Vibration Environment, Zhengzhou University, Zhengzhou, China, 2017.

[28] W. Ren, G. Du, and Y. Pan, "The expermental study of rockburst prevention through vibration inducing crevasse in coalmass," Journal of Fuxin Mining Institute, vol. 16, no. 6, pp. 687-690, 1997.

[29] W. Ren, Y. Pan, and S. Song, "The experimental study of the coalmass crevasse growing after coalmass vibrated with different frequency," Journal of Liaoning Technical University, vol. 17, no. 6, pp. 3-5, 1998.

[30] Y. Pan, G. Du, Y. Zhang, L. Wang, and M. Zhang, "Study on the mechanism of rockburst prevention by coalmass vibration," Chinese Journal of Rock Mechanics and Engineering, vol. 18, no. 4, pp. 3-5, 1999.

[31] C. Li, X. Sun, T. Gao, Y. Sun, B. Xie, and X. Xu, "Research on the variation characteristics of natural frequency in the process of coal and rock vibration damage," Journal of China Coal Society, vol. 40, no. 10, pp. 2422-2429, 2015.
[32] C. Li, X. Sun, T. Gao, B. Xie, and X. Xu, "Coal and rock vibration failure and the characteristics of micro-seismic signals," Journal of China Coal Society, vol. 40, no. 8, pp. 1834-1844, 2015.

[33] W. Zhao, Diffusion Dynamics of Rapid Desorption of Gas from Pulverized Coal and its Influence on Transporting Coal and Rock in Outbursts, China University of Mining and Technology, Xuzhou, China, 2018.

[34] H. Guo, L. Yuan, Y. Cheng, K. Wang, and C. Xu, "Experimental investigation on coal pore and fracture characteristics based on fractal theory," Powder Technology, vol. 346, pp. 341-349, 2019.

[35] C. R. Clarkson, N. Solano, R. M. Bustin et al., "Pore structure characterization of North American shale gas reservoirs using USANS/SANS, gas adsorption, and mercury intrusion," Fuel, vol. 103, pp. 606-616, 2013.

[36] F. Wang, Y. Cheng, S. Lu, K. Jin, and W. Zhao, "Influence of coalification on the pore characteristics of middle-high rank coal,” Energy \& Fuels, vol. 28, no. 9, pp. 5729-5736, 2014.

[37] H. Fu, D. Tang, T. Xu et al., "Characteristics of pore structure and fractal dimension of low-rank coal: a case study of Lower Jurassic Xishanyao coal in the southern Junggar Basin, NW China," Fuel, vol. 193, pp. 254-264, 2017.

[38] S. Zhou, D. Liu, Y. Cai, Y. Yao, Y. Che, and Z. Liu, "Multiscale fractal characterizations of lignite, subbituminous and high-volatile bituminous coals pores by mercury intrusion porosimetry," Journal of Natural Gas Science and Engineering, vol. 44, pp. 338-350, 2017.

[39] S. Yu, J. Bo, L. Fengli, and L. Jiegang, "Structure and fractal characteristic of micro- and meso-pores in low, middle-rank tectonic deformed coals by CO 2 and N 2 adsorption," Microporous and Mesoporous Materials, vol. 253, pp. 191-202, 2017.

[40] G. Sang, S. Liu, R. Zhang, D. Elsworth, and L. He, "Nanopore characterization of mine roof shales by SANS, nitrogen adsorption, and mercury intrusion: impact on water adsorption/ retention behavior," International Journal of Coal Geology, vol. 200, pp. 173-185, 2018.

[41] Y. Li, Y. Zhang, L. Zhang, and J. Hou, "Characterization on pore structure of tectonic coals based on the method of mercury intrusion,carbon dioxide adsorption and nitrogen adsorption," Journal of China Coal Cociety, vol. 44, no. 4, pp. 1188-1196, 2019.

[42] W. Han, G. Zhou, D. Gao et al., "Experimental analysis of the pore structure and fractal characteristics of different metamorphic coal based on mercury intrusion-nitrogen adsorption porosimetry," Powder Technology, vol. 362, pp. 386-398, 2020.

[43] K. Jin, Y. Cheng, Q. Liu et al., "Experimental investigation of pore structure damage in pulverized coal: implications for methane adsorption and diffusion characteristics," Energy \& Fuels, vol. 30, no. 12, pp. 10383-10395, 2016.

[44] L. Wang, G. Zhang, J. Liu, X. Chen, and Z. Li, "Effect of the pore structure on adsorption and diffusion migration of different rank coal samples," Energy \& Fuels, vol. 34, no. 10, pp. 12486-12504, 2020.

[45] Z. Wang, Y. Cheng, Y. Qi, R. Wang, L. Wang, and J. Jiang, "Experimental study of pore structure and fractal characteristics of pulverized intact coal and tectonic coal by low temperature nitrogen adsorption," Powder Technology, vol. 350, pp. 15-25, 2019.

[46] Y. Yao, D. Liu, D. Tang et al., "Fractal characterization of seepage-pores of coals from China: an investigation to permeability of coals," in Proceedings of the Annual Conference of 
the International Association for Mathematical Geology, IAMG 2007, pp. 415-420, China University of Geosciences, Beijing, China, August 2007.

[47] G. Lu, J. Wang, C. Wei et al., "Pore fractal model applicability and fractal characteristics of seepage and adsorption pores in middle rank tectonic deformed coals from the Huaibei coal field," Journal of Petroleum Science and Engineering, vol. 171, pp. 808-817, 2018.

[48] Y. Zhao, S. Liu, D. Elsworth, Y. Jiang, and J. Zhu, "Pore structure characterization of coal by synchrotron small-angle $\mathrm{X}$-ray scattering and transmission electron microscopy," Energy \& Fuels, vol. 28, no. 6, pp. 3704-3711, 2014.

[49] Y. Xu, X. Chen, W. Zhao, and P. Chen, "Effect of water intrusion on the characteristics of surface morphology and pore fracture spaces in argillaceous meagre coal," Journal of Natural Gas Science and Engineering, vol. 81, Article ID 103404, 2020.

[50] J. Tian, Research on Dynamic Model and Dynamic Characteristic of Vertical Axis Road-Header, Liaoning Technical University, Fuxin, China, 2002.

[51] Y. Zhao, Study on Property of Low Frequency Vibration to Coupled Fields Seepage, Xi'an University of Science and Technology, Xi'an, China, 2015.

[52] Y. Yao, D. Liu, D. Tang, S. Tang, and W. Huang, "Fractal characterization of adsorption-pores of coals from North China: an investigation on $\mathrm{CH} 4$ adsorption capacity of coals," International Journal of Coal Geology, vol. 73, no. 1, pp. 27-42, 2008.

[53] J.-F. Zhu, J.-Z. Liu, Y.-M. Yang, J. Cheng, J.-H. Zhou, and K.-F. Cen, "Fractal characteristics of pore structures in 13 coal specimens: relationship among fractal dimension, pore structure parameter, and slurry ability of coal," Fuel Processing Technology, vol. 149, pp. 256-267, 2016. 